Revista Estudios, (36), 2018.

Junio 2018-Noviembre 2018

ISSN 1659-3316

Vázquez Parra José Carlos

García Caballero Lorena

IV Sección: Tres visiones sobre la Etica

\title{
La acción en perspectiva. Una aproximación desde la neuroética y la teoría de la racionalidad Elsteriana
}

José Carlos Vázquez Parra

Escuela de Humanidades y Educación Tecnológico de Monterrey en Guadalajara, México

jcvazquezp@itesm.mx

https://orcid.org/0000-0001-9197-7826

Lorena García Caballero Escuela de Humanidades y Educación Tecnológico de Monterrey en Guadalajara, México

lorena.caballero@itesm.mx

https://orcid.org/0000-0002-5532-9562

Recibido: 5 de enero de 2018

Aceptado: 9 de febrero de 2018

\section{Resumen}

El artículo busca hacer una reflexión sobre la acción y la toma de decisiones desde la neuroética y la teoría de la racionalidad elsteriana. En este análisis, se pretende escudriñar en los elementos que son considerados como constituyentes del acto desde ambos enfoques, determinando qué rol juega la racionalidad al momento de la toma de decisiones. A pesar de que ambas propuestas, la neuroética y la propuesta elsteriana, valoran la racionalidad sobre cualquier otro elemento del comportamiento, en la conclusión se ha podido identificar que existen nociones, como las emociones, que, aunque muchas veces no se consideran, desempeñan un rol tan relevante al momento de tomar decisiones, que pueden incluso constituirse como elementos en común entre ambas propuestas teóricas.

\section{(C) $(00$}

La Revista Estudios es editada por la Universidad de Costa Rica y se distribuye bajo una Licencia Creative Commons Atribución-NoComercial-CompartirIgual 3.0 Costa Rica. Para más información envíe un mensaje a 
Palabras clave: Toma de decisiones; elección; emociones; ideal; realidad

The action in perspective. An approach from neuroethics and the theory of Elsterian rationality

\begin{abstract}
The article seeks to make a reflection on the action and the decision making from the neuroethics and the elsterian theory of the rationality. In this analysis, the authors seek to scrutinize the elements that are considered as constituents of the act from both approaches, determining what role rationality plays at the moment of decision making. In spite of the fact that both proposals value rationality over any other element of the agent's behavior, in the conclusion it has been possible to identify that there are notions, such as emotions, that play a very relevant place, even being the meeting point between both theories.
\end{abstract}

Key words: Decision making; election; emotions; ideal; reality

\title{
1. Introducción
}

La acción es uno de los temas fundamentales de la reflexión filosófica y del análisis ético, no solo para los contemporáneos, sino desde el inicio mismo de la filosofía con los planteamientos de Aristóteles o las aportaciones posteriores de David Hume. Sin embargo, querer ahondar en un tema tan complejo como la acción, nos obliga a referirnos a ella a partir de momentos que desempeñan un papel fundamental en su desarrollo, como es el caso específico de la elección, en la que se nos permite analizar cuál de las alternativas de actuación es la más óptima; y por supuesto la toma de decisiones, en donde precisamente se discute qué acción realizar y cual no.

En nuestra sociedad, el análisis de la toma de decisiones se ha convertido en un tema de discusión tan relevante, que sin importar si la decisión es de menor o mayor trascendencia, ésta es vista como una acción en sí misma, la cual tiene

\section{(c) (i) (2) (2)}

La Revista Estudios es editada por la Universidad de Costa Rica y se distribuye bajo una Licencia Creative Commons Atribución-NoComercial-CompartirIgual 3.0 Costa Rica. Para más información envíe un mensaje a 
ISSN 1659-3316

Vázquez Parra José Carlos

García Caballero Lorena

una relación directa con el agente, sus creencias, sus deseos y, sobre todo, con un determinado fin u objetivo. De tal manera, la acción de decidir, tiene una categoría especial dentro de la vida humana, pues como su etimología lo señala, implica un corte, un rompimiento, una separación que se hace dentro de un proceso de evaluación de las diferentes partes que integran un dilema.

Sin embargo, cabe señalar que hay decisiones que no "rompen", o que referencian a un rompimiento menor, por ejemplo, decidir tomar un baño, en contraposición a otras que llevan a la decisión a un estado más crítico, como lo sería el actuar de un terrorista. Sea como sea, ambas son decisiones en las que el agente debe elegir entre dos o más alternativas de acción, y que, a su vez, de cada una de esas opciones se desprenden consecuencias inciertas, y que por consiguiente es indispensable elegir tomar una de entre ellas. Así, desde el abordaje aristotélico de la phronesis (prudencia) (EN VI, cap. 5) y la deliberación como principio de la acción (EN VI, cap. 2: 1139aํ), la búsqueda humana para alcanzar los fines más excelsos a partir de los mejores medios y las acciones más óptimas, así como comprender el porqué de dichos comportamientos es, según Picavet (2001), un objetivo que ha sido heredado por los pensadores de todas las épocas y por múltiples áreas de conocimiento.

Por consiguiente, el presente artículo busca hacer una reflexión desde dos enfoques que particularmente reflexionan sobre la acción; la neuroética ${ }^{1}$, que profundiza en gran medida en el carácter biológico del acto y la teoría de la racionalidad elsteriana, propuesta teórica del sociólogo Jon Elster que se enfoca en aquellos elementos que respaldan lo que los seres humanos conocemos como racionalidad. El objetivo es presentar al lector una visión multidisciplinaria integral de las implicaciones que conlleva la elección, las decisiones y el acto en general, para

\footnotetext{
${ }^{1}$ Entenderemos por neuroética a la propuesta que hace Judy llles y Thomas Raffin (Illes \& Racine, 2002) cuando señalan que la neuroética es una nueva disciplina bioética surgida de manera formal en el 2002 para agrupar todos aquellos temas teóricos y prácticos que tienen consecuencias morales y sociales en las ciencias neurológicas, tanto en el laboratorio como en la atención sanitaria o en la vida social.
}

La Revista Estudios es editada por la Universidad de Costa Rica y se distribuye bajo una Licencia Creative Commons Atribución-NoComercial-Compartirlgual 3.0 Costa Rica. Para más información envíe un mensaje a 
promover de tal manera, la necesidad de considerar elementos que usualmente se presumen, y que limitan claramente la posibilidad de explicar y comprender el actuar humano. El motivo de relacionar esta visión biológica de la ética con una perspectiva de análisis conductual de carácter más social como la propuesta por el noruego Jon Elster, radica en el cuestionamiento que ambos enfoques terminan gestando sobre la posibilidad de una racionalidad objetiva, mismo que obliga a ver el acto desde una perspectiva más amplia.

\section{Contenido}

\subsection{La acción desde la neuroética}

El inicio del libro El error de Descartes del neurólogo Antonio Damasio (2006) comienza explicando el caso de Phineas P. Gage, quizá uno de los más emblemáticos a la hora de abordar temas de neuroética, el cual además, es un parte aguas en la evolución de las neurociencias.

Damasio narra lo que aconteció en Nueva Inglaterra, un verano de 1848 a un joven de veinticinco años llamado Phineas P. Gage. El joven en cuestión, trabajaba en tender una nueva línea para la expansión de un ferrocarril, teniendo bajo su supervisión un buen número de hombres. A este joven le correspondía tocaba supervisar tanto el terreno en el que se estaba gestando la expansión férrea como lo qué se hacía, así como el método empleado; era un trabajador tan capaz -según palabras de sus propios jefes-, que incluso le confiaban tareas tan complejas y peligrosas como la detonación (Damasio, 2006, p. 22). En una de las detonaciones que Gage hacía reiteradamente se distrae por breves instantes pues un compañero le llama; aparta la vista del barreno y sucede una tragedia: "El hierro penetra por la mejilla izquierda de Gage, perfora la base del cráneo, atraviesa la parte frontal del mismo y sale a gran velocidad a través de la parte superior de la cabeza" (Damasio, 2006, p. 23).

\section{(c) (i) (9) (2)}

La Revista Estudios es editada por la Universidad de Costa Rica y se distribuye bajo una Licencia Creative Commons Atribución-NoComercial-CompartirIgual 3.0 Costa Rica. Para más información envíe un mensaje a 
ISSN 1659-3316

Vázquez Parra José Carlos

García Caballero Lorena

El neurólogo portugués continua el relato con una prosa digna de cualquier literato reconocido, incluyendo detalles incluso de los titulares de la época que daban cuenta de lo acontecido. Para fines de esta reflexión basta resumir los elementos más importantes de ese hecho y sus implicaciones para este artículo. En primer lugar, dada la seriedad de la lesión, resultando sorprendente que aquél joven siguiera con vida. En segundo lugar -y no menos importante-, que su vida había cambiado por completo. El médico que lo trató señaló que gracias a su recuperación física exitosa. "Gage podía sentir, oír y ver, y no tenía parálisis de extremidades o lengua. Había perdido visión en su ojo izquierdo pero la del derecho era perfecta" (Damasio, 2006, p. 26). A pesar de lo significante de su mejoría, el médico había caído en la cuenta de un cierto desbalance en las facultades intelectuales y las "propensiones animales" del joven.

De ser una persona sumamente responsable, respetuosa, capaz y trabajadora; Gage se convirtió -después del accidente-, en prácticamente otra persona: irresponsable, desinhibido, grosero, agresivo, falto de empatía y consideración para con los demás. La relación y análisis que se puede establecer a partir del cambio de personalidad y comportamiento de una persona como Gage que -a partir de sufrir una lesión cerebral-, deje de ser quien era, es justamente la consideración que da cabida al inicio de la reflexión de la perspectiva de la neuroética en la toma de decisiones.

Como se señala en un inicio de esta reflexión, el caso de Gage ha sido un referente en las discusiones neuroéticas y -de manera más general-, un parte aguas en el desarrollo de las neurociencias. A partir de este caso, las neurociencias y los cuestionamientos que implicaban análisis moral siguieron una larga tradición que tomó como punto de partida el estudio de personas que habían sufrido una especie de daño cerebral. La relación y la pertinencia son claras: al ver que existe una relación directa entre la personalidad y, por tanto, entre la manera en la que se actúa normalmente y el funcionamiento del cerebro, surgen varias preguntas del tipo: ¿la conducta se limita y se explica en términos de una red neuronal de impulsos? ¿La

La Revista Estudios es editada por la Universidad de Costa Rica y se distribuye bajo una Licencia Creative Commons Atribución-NoComercial-CompartirIgual 3.0 Costa Rica. Para más información envíe un mensaje a 
ISSN 1659-3316

Vázquez Parra José Carlos

García Caballero Lorena

manera en la que se toman decisiones se limita a la segregación de una serie de neurotransmisores y a la activación de ciertas áreas del cerebro?

Como seres éticos, una de las improntas que caracteriza al ser humano como tal es la capacidad de elegir, ya que estructural y potencialmente es un ser que elige constantemente. Desde una postura ética tradicional, el acto de la elección conlleva: la acción consciente, voluntaria, libre y responsable. Ahora bien, con los avances en las neurociencias ya no es posible pensar este tipo de dimensiones éticas del hombre sólo a la luz de la ética; es necesario poner ambas disciplinas, la ética y las neurociencias, en un diálogo, de modo que arrojen una perspectiva más rica y fidedigna de cuestiones que antes de no eran posibles de cuantificar o registrar fácticamente.

Diálogo sí, reduccionismo no, y es que el peligro -por llamarle de algún modo-, de abordar este aspecto como el proceso de elección con un enfoque neuroético, es el de caer en un reduccionismo en el que se considere todo acto consciente, como un producto de compuestos bioquímicos y fisiológicos. Lejos de conseguir el enriquecimiento del que hablaba líneas arriba, se caería en un solipsismo disciplinar que es uno de los aspectos que suele trascender al unir disciplinas como la ética y las neurociencias.

Resulta pertinente, señalar que, ya que en todas las acciones suele plantearse como parte fundamental la deliberación ${ }^{2}$, esto da claramente cabida a hablar de neuroética, ya que para hablar de actos deliberativos se tiene -necesariamente-, que hablar del sistema nervioso central (SNC). El diccionario Oxford de la mente señala que: El sistema nervioso central es la materia física que proporciona a su poseedor las formas de conducta, determinadas genéticamente, y también las maneras de cambiar esa conducta. Lo que se ha heredado es la estructura, que se estudia como

\footnotetext{
${ }^{2}$ Juan Carlos Velasco en su artículo Democracia y Deliberación Pública (2009) señala que: "La deliberación es esencial para la racionalización, tanto de las decisiones individuales como de las colectivas. De hecho, la deliberación, en cuanto procesos en el que se comparan y sopesan las diversas posibilidades de acción según sus ventajas o desventajas respectivas y dentro del objeto de atender a un fin preciso, puede ser puesta en marcha tanto en el ámbito estrictamente personal como en espacios públicos" (71)
}

\section{(c) (i) (2)}

La Revista Estudios es editada por la Universidad de Costa Rica y se distribuye bajo una Licencia Creative Commons Atribución-NoComercial-CompartirIgual 3.0 Costa Rica. Para más información envíe un mensaje a revistaestudios.eeg@ucr.ac.cr. 
ISSN 1659-3316

fisiología. A veces conviene, y a veces confunde, clasificar algunas partes del funcionamiento como actividades mentales. Pero esto no implica que tras este funcionamiento una estructura a la que se podría llamar mente (Gregory, 1995, pág. 1039). En líneas generales, el SNC tiene dos partes: el compuesto por el cerebelo y la médula espinal y el sistema nervioso periférico (SNP). SNC y SNP se relacionan estrechamente a través de músculos y receptores que funcionan electro- físicaquímicamente. Esto se traduce en impulsos de entrada y salida de la información, esto es, el procesamiento cerebral. Toda actividad consciente muestra que "somos organismos que han evolucionado para solucionar problemas en un mundo real utilizando los medios que sean necesarios. Para dirigir esta flexibilidad hemos adquirido sistemas de control que guían nuestro comportamiento y nuestro pensamiento, sistemas que reciben el nombre de "conciencia" (Bridgeman, 1991, pág. 548).

Ahora bien, desde esta perspectiva neurobiológica, el tema de la elección encuentra dos puntos fuertes de apoyo: por un lado, le da un "lugar" específico a los actos voluntarios libres que -en la ética tradicional- no se podían "ubicar" en el sentido estricto de la expresión; pero por otro lado, al entender los actos voluntarios libres como procesos neurobiológicos, no sólo se pueden abordar de manera más concreta pues encuentran su lugar y arraigo en una determinada geografía cerebral, sino que también pueden colocarse en un nivel de análisis predictivo. Así pues: ¿Se pueden explicar los actos voluntarios desde esta perspectiva? La respuesta es sí, ya que al conocer y comprobar que la corteza cerebral no sólo ha marcado de manera anatómica la individualidad, sino que también, controla las funciones superiores del cerebro, se permite ofrecer una visión neuroética del actuar humano.

En cuanto a la toma de decisiones, de manera concreta, la neuroética hace referencia a la consciencia. Bridgeman (1991) considera que la conciencia tiene que cumplir con cuatro funciones: planificación, ejecución, dirección de la atención y recuerdos. Estos componentes resultan claves en el proceso de control de nivel superior. Si esto se traslada al ejemplo señalado al inicio de este apartado, el hecho 
ISSN 1659-3316

Vázquez Parra José Carlos

García Caballero Lorena

de que las lesiones se dieran en la corteza prefrontal causa, entre otras cosas, pérdida del control de la conducta y severos problemas para ejecutar los planes. Esto habla de la base biológica de las decisiones y de cómo el área del cerebro encargada de tales funciones, al ser afectada, tiene injerencia directa en la estructura y dimensión de la acción, es decir, que los procesos de toma de decisión se encuentran relacionados con una parte biológica concreta del cerebro, de la cual depende el que el proceso se genere óptima y adecuadamente. Procesos químicos y neuroanatómicos regulares dan origen a la acción consciente; procesos químicos y neuroanatómicos que presentan algún tipo de daño, se expresan en acciones y tomas de decisiones irregulares y atípicas.

Lo dicho hasta ahora da cuenta de la visión general desde la que parte una visión neuroética de la toma de decisiones, sin embargo, existen propuestas teóricas, como en todas las áreas académicas, que pudieran poner en entredicho una visión tan objetiva del comportamiento con una raíz puramente fisiológico. Al igual que Jon Elster llega a cuestionar la propuesta del hombre económico contemporáneo, el modelo dual de J. Greene, explicado por Lydia Feito (2015), viene a considerar la necesidad de incluir más elementos que únicamente los que ofrece biológicamente el cerebro.

Como el mismo nombre del modelo lo indica, la postura de Green defiende que el razonamiento (prácticamente sólo cognición) y emoción cuentan con aparatos anatómicos muy distintos, es decir, duales. Incluso, en la toma de decisiones morales complejas, se piensa que ambas dimensiones pueden entrar en conflicto, tomando la última palabra -por decirlo de algún modo-, la dimensión racional; es decir, que las áreas cerebrales cognitivas son capaces de anular las emocionales. Esta postura cree que domina una "elección racional” sobre una "elección emocional" (Feito, 2015, pág. 83)

Como señala Feito, los experimentos de J. Greene consisten en plantear escenarios morales en los que se requiere la toma de una decisión, tratando de determinar si las áreas que controlan las emociones se activan cuando se dan 
ISSN 1659-3316

Vázquez Parra José Carlos

García Caballero Lorena

respuestas a dichos dilemas. También se preguntan si hay diferencia entre los escenarios "personales" y los "impersonales". La cuestión de los escenarios personales e impersonales reviste una importancia crucial a la hora de comprender el modelo dual en la toma de decisiones.

Feito presenta de manera concreta dos ejemplos en donde Geene ponía a prueba a la población muestra para analizar sus respuestas morales. Por un lado, les presentaban el dilema del tranvía que propone "una situación en la que una persona se encuentra ante una vía en la que están cinco personas, cuando observa que se dirige hacia ellas un tranvía a gran velocidad que, con toda seguridad, las arrollará" (Feito, 2015, p. 84). A la persona se le dice que tiene la oportunidad de desviar una de las agujas del tranvía, provocando así la muerte de una persona que se encuentra en la otra vía, pero no así la muerte de cinco. La pregunta de fondo para el sujeto de estudio sería algo así como: “¿estaría usted dispuesto a matar a una persona, pero salvando a cinco?" El dilema del tranvía es presentado en una segunda versión pero que marca una diferencia importante a la hora de analizar en qué aspectos de la dimensión neurobiológica se pone el énfasis a la hora de tomar una decisión: "En este caso, el protagonista se encuentra en una pasarela que pasa por encima de la vía por la que, como en el caso anterior, circula un tranvía que va a matar a cinco personas. A su lado hay un desconocido, una persona de gran tamaño. La pregunta en este caso es si empujaría al desconocido de modo que, al caer, pudiera parar el tranvía, muriendo, pero salvando la vida de las otras cinco personas" (Feito, 2015, p. 85).

Los resultados y conclusiones que arrojan las respuestas de los participantes sorprende al mismo Greene, ya que la mayoría concuerda en que sería aceptable hacer el cambio de agujas que mataría a una persona, pero salvaría a cinco, mientras que estarían en desacuerdo en empujar al desconocido; empero esta acción conllevaría cinco muertes. Las diferencias parecen sutiles, pero no lo son, el trasfondo moral consiste en optar por morir y dejar morir. La diferencia de respuestas

\section{(c) (i) (2)}

La Revista Estudios es editada por la Universidad de Costa Rica y se distribuye bajo una Licencia Creative Commons Atribución-NoComercial-CompartirIgual 3.0 Costa Rica. Para más información envíe un mensaje a 
ISSN 1659-3316

Vázquez Parra José Carlos

García Caballero Lorena

-según Greene, tiene su origen en un aspecto emocional; a saber, la aversión de dañar a otro.

Sin embargo, a pesar de estos resultados, Greene y sus colaboradores abogan por una predominancia del razonamiento cognitivo, pues se dan cuenta de que, al tomar dichas decisiones, se activan zonas cerebrales relacionadas a la cognición y al razonamiento abstracto (corteza singular anterior y corteza prefrontal dorsolateral) en los agentes participantes (Feito, 2015). Resulta curioso -y contradictorio-, que, pese a la preeminencia de la razón y la activación de las zonas cerebrales al hacer uso de ésta, las decisiones finales de las personas tengan la impronta de un mayor peso emocional. Lo que igualmente contradice el hecho de que, conforme a su actividad cerebral, los participantes debieron dar respuestas meramente racionales.

Como usualmente se considera en la tradición filosófica moderna, tanto desde las corrientes aristotélicas, kantianas como algunas propuestas utilitaristas, la respuesta emocional se presenta como algo de menor rango y subordinado a la toma de decisiones basada en la razón, lo que parece ser, a partir de este experimento, no es tan cierto. Así: Las pasiones que inclinan al hombre a buscar la paz, son el miedo a la muerte, el deseo de obtener las cosas para vivir cómodamente, y la esperanza de que, en su trabajo, puedan conseguirlas. Y la razón sugiere convenientes normas de paz, basándose en las cuales los hombres pueden llegar a un acuerdo" (Hobbes, 1989, pág. 9). Parece ser que lo que dijo Hobbes hace aproximadamente trescientos setenta y cinco años sigue siendo tan vigente como lo que neurocientíficos y eticistas actuales sostienen; con la pequeña diferencia de que ahora se fundamentan en pruebas de resonancias magnéticas funcionales.

Más allá de la conclusión a la que llegan los fieles defensores del modelo dual, pareciera que, en la experiencia misma, no se puede ser tan tajante, ya que no resulta sencillo dejar en un elemento medible el juicio impersonal y objetivo, separándosele por completo de la carga afectiva. Aunque el modelo dual de la neuroética siga apoyando la visión tradicional defendida por la filosofía (la razón como

\section{(c) (i) (2)}

La Revista Estudios es editada por la Universidad de Costa Rica y se distribuye bajo una Licencia Creative Commons Atribución-NoComercial-CompartirIgual 3.0 Costa Rica. Para más información envíe un mensaje a 
ISSN 1659-3316

Vázquez Parra José Carlos

García Caballero Lorena

superior y en dominio de las emociones); no cabe duda de que, con los avances actuales en neurociencias se está empezando a entender el binomio razón- emoción como una "danza"; en la que a veces sea una quien tome el protagonismo sobre la otra. Si esta manera de entender a la razón y las emociones sigue el curso dialógico que le ha impreso la neuroética, quizá esperen, en un futuro no muy lejano, reflexiones muy distintas sobre la naturaleza humana y la propia estructura ética del hombre.

\subsection{La acción desde la propuesta Elsteriana}

Jon Elster, filósofo y teórico social nacido en Noruega, considera que uno de los mayores problemas que se puede dar al momento de reflexionar sobre la acción y la toma de decisiones, es presumir que todo está dicho. De manera concreta, sus trabajos sobre análisis del comportamiento se enfocan en cuestionar la teoría de la elección racional que los economistas y utilitaristas clásicos consideraban como un excelente medio de comprensión de los actos.

La teoría de la elección racional se sustenta bajo el principio de que la racionalidad de los actos es algo presumible e intrínsecamente dado, lo que permite alcanzar cierta certidumbre en la previsión de las consecuencias de la acción. Esta presunción de racionalidad se basa en la idea de que cualquier agente tiene siempre la posibilidad de hacer elecciones racionales, por lo que el análisis de las acciones debe centrarse únicamente en el momento mismo de la elección y la toma de decisiones, por lo tanto, no hay necesidad de escudriñar en la génesis de las preferencias. De esta forma, el abordaje acotado sobre las acciones permite hacer previsiones mucho más certeras sobre las consecuencias, pues en su análisis no incluyen factores que podrían alterar la elección del agente como por ejemplo sus deseos, emociones, creencias o posibilidades, presumiendo que el individuo siempre es racional.

Sin embargo, esta presunción de una racionalidad ideal, así como llega a ser muy atractiva para muchos académicos que trabajan sobre la teoría de la elección

\section{(c) (i) (2)}

La Revista Estudios es editada por la Universidad de Costa Rica y se distribuye bajo una Licencia Creative Commons Atribución-NoComercial-CompartirIgual 3.0 Costa Rica. Para más información envíe un mensaje a revistaestudios.eeg@ucr.ac.cr. 
ISSN 1659-3316

Vázquez Parra José Carlos

García Caballero Lorena

racional, como Mancur Olson, Keneth Arrow, Raymon Aron y John Roemer, también se convierte en el mayor limitante de esta propuesta teórica, ya que, aunque la facultad maximizadora y predictiva de esta teoría parece apegarse muy bien a la noción del homo economicus propuesta asociada a menudo con las ideas de pensadores como Adam Smith y David Ricardo, al considerarse al agente como un ente racional, ésta demerita en gran medida el papel que desempeñan el resto de los elementos constitutivos de la acción, sí como aleja al ser humano de la toma de decisiones realistas. Aunque la teoría de la elección racional tenía una raíz primordialmente enfocada en entender y modelar formalmente el comportamiento social y económico, poco pudo hacer para explicar las crisis, los fraudes o las quiebras de las grandes empresas pues, aunque los economistas buscaban hacer predicciones del futuro económico de las naciones y las organizaciones, estos no lograban predecir los resultados económicos (Rábade, 1994).

Jon Elster en sus obras más actuales, como El Desinterés (2011) y L'Irrationalité (2010), plantea que para que la propuesta de la elección racional pueda ser realmente explicativa o predictiva, ésta debe suponer un contexto en donde no exista conflicto de visiones ni de intereses, es decir, casi una situación utópica en la que el sujeto posea o disponga de todo tipo de información, teniendo adicionalmente la capacidad para analizarla y evaluarla, así como tener a su alcance todos los recursos disponibles e incluso el tiempo necesario para poner en marcha su decisión. Lógicamente esto atenta contra la realidad llena de incertidumbre que viven los agentes (Elster, 2000).

Elster considera que dejar de presumir la racionalidad, aunque parece lo más sensato, abre cabida a la necesidad de analizar una serie de elementos y características de los actos que pudieran llegar a cuestionar la capacidad real de los seres humanos de ser racionales. Para que un agente pueda alcanzar la racionalidad desde la propuesta planteada por Jon Elster (2007), el acto debería ser evaluado a partir de un filtro de análisis bastante complejo, mismo que abarca:

\section{(c) (i) (2)}

La Revista Estudios es editada por la Universidad de Costa Rica y se distribuye bajo una Licencia Creative Commons Atribución-NoComercial-CompartirIgual 3.0 Costa Rica. Para más información envíe un mensaje a 
ISSN 1659-3316

Vázquez Parra José Carlos

García Caballero Lorena

a) Que los deseos que guían la acción sean autónomos, es decir, que no estén afectados o alterados por motivaciones ocultas, entre las que se encuentra la pasión, las emociones, las adicciones, entre otras.

b) Que las alternativas que componen la escala de preferencias, se basen en creencias racionales, es decir, que se sustenten en evidencia e información óptima y real, misma que sea suficiente para evitar creencias sesgadas, mas no tanta como para dar pauta a un caso de hiperracionalismo.

c) Que la escala de preferencias, al ser constituida por alternativas sustentadas en tales creencias racionales, implique una valoración y función de utilidad lo más óptima y realista posible, basada en una evaluación del agente conforme a lo que para él es importante y no tanto a motivaciones ocultas o externas como el miedo, la presión social, etc.

d) Que la acción a realizarse sea aquella que, conforme a todo el análisis anterior, se apegue más a la consecución de los fines pretendidos por el agente, apegándose a la maximización de las utilidades y evitando por medio de un buen proceso reflexivo, casos de indeterminación o una posible debilidad de la voluntad al momento de actuar, cuestiones que podrían arruinar todo el proceso de reflexión realizado.

En sus últimos libros como El Desinterés (2011) y L'Irrationalité (2010), Elster reconoce que los requisitos necesarios para esta racionalidad llegaban a ser tan difíciles de conseguir, que solo le restaba renunciar a la supremacía del poder explicativo de la teoría de la elección racional, considerando que todas las limitaciones que tenía este modelo, eran en sí mismas, limitaciones propias de la racionalidad (Doménech, 1991, pág. 33), la cual aunque llega a ser una buena aportación teórica y descriptiva, no es ni explicativa y mucho menos predictiva.

Este cuestionamiento a la posibilidad de alcanzar la racionalidad de los actos, lleva a que la propuesta elsteriana se abra a elementos que viabilicen hacer explicaciones más precisas de la acción, considerando como alternativa, al igual

\section{(c) (i) (2)}

La Revista Estudios es editada por la Universidad de Costa Rica y se distribuye bajo una Licencia Creative Commons Atribución-NoComercial-CompartirIgual 3.0 Costa Rica. Para más información envíe un mensaje a 
ISSN 1659-3316

Vázquez Parra José Carlos

García Caballero Lorena

que lo hizo la neuroética, el que las emociones y la racionalidad tuvieran alguna relación, considerándolas como elementos motivacionales de los deseos, así como componentes del desarrollo y fundamentación de las creencias.

\subsection{El rol de las emociones en la acción elsteriana}

Dentro de las ciencias de la conducta (psicología, psiquiatría, pedagogía, etc.), las emociones son estudiadas a partir de su aspecto cognitivo, enfocándose primordialmente en su origen y desarrollo. Sin embargo, lo que Elster (1989, pág. 67) propone es el análisis de su poder motivacional, considerando que aunque las emociones pueden proporcionar un sentido de dirección al acto conforme a la generación de deseos, igualmente pueden impedir firmemente que se llegue a tales objetivos. Por ello, Elster valora que:

Una tipología amplia de los mecanismos distorsionantes se puede elaborar si observamos que, al igual que los estados generales generados por estos mecanismos, estos dispositivos pueden ser cognoscitivos o afectivos en el carácter. Así mismo, la falta de racionalidad puede deberse a procesos cognoscitivos equivocados o a influencias indebidas procedentes de algún impulso afectivo, como es el caso de las pulsiones. Las pulsiones modelan a los deseos y las creencias, pero no son en sí mismas deseos, puesto que no son conscientes ni conocidas para la persona que las experimenta. Por ello, éstas deben ser entendidas como fuerzas psíquicas no conscientes que se engranan en función de la búsqueda de placer a corto plazo, o sea que son opuestas a los deseos conscientes, que pueden privarse de placer a corto plazo para alcanzar cierto beneficio o ganancia a largo plazo (Elster, 1988, págs. 41-42).

\section{(C) 100}

La Revista Estudios es editada por la Universidad de Costa Rica y se distribuye bajo una Licencia Creative Commons Atribución-NoComercial-Compartirlgual 3.0 Costa Rica. Para más información envíe un mensaje a 
ISSN 1659-3316

Vázquez Parra José Carlos

García Caballero Lorena

Adicionalmente, Elster (1989, pág. 75) no pasa por alto el hecho de que el estudio de los poderes motivacionales de las emociones le obligan al estudio de su poder distorsionador, ya que no se puede contar con la motivación emocional sin el riesgo de que tales emociones afecten en la autonomía y por ende a la racionalidad de la actuación misma.

Así, y con la intención de lograr un acercamiento al tema, Elster (2007, págs. 167-168) clasifica a las emociones en tres grandes grupos; emociones evaluativas (vergüenza, desprecio, culpa, ira, indignación, altivez, agrado, orgullo, gratitud y admiración), emociones generadas por la posesión de otros (envidia, indignación, simpatía, compasión, resentimiento y regodeo) y las emociones positivas o negativas generadas por lo bueno o malo que le pasa al agente (alegría y pena).

Estas emociones (haciendo referencia a las anteriormente comentadas), expresa Elster (2007, págs. 171-177), gozan de un vínculo con la acción a partir de una tendencia a la misma, ya que una motivación emocional no solo induce el deseo por actuar, sino también a que se actué lo antes posible. Elster reconoce que tal urgencia puede afectar rotundamente la racionalidad tanto de los deseos, como de las creencias, afectando la autonomía, nublando el juicio y alterando la recolección de información, ocasionando que se haga presente el citado poder distorsionador con el que cuentan las emociones (Elster, 2002). En particular, las emociones inducen expectativas poco realistas en cuanto a lo que podemos desear, hacer y lograr, así como creencias poco confiables acerca de las opciones que enmarcan nuestra escala de preferencias (Elster, 1989, pág. 75).

Sin embargo, esta perspectiva, de que las emociones suponen en gran medida un estorbo para la racionalidad, no debe ser la única percepción que se tenga de las mismas, ya que el mismo Elster (2002, pág. 343) también considera que en algunos casos, las emociones pueden fomentar la racionalidad de las decisiones, ya sea deshaciendo los empates generados por la indeterminación o llevando la atención del agente a los rasgos más destacados de una situación.

\section{(c) (i) (2)}

La Revista Estudios es editada por la Universidad de Costa Rica y se distribuye bajo una Licencia Creative Commons Atribución-NoComercial-CompartirIgual 3.0 Costa Rica. Para más información envíe un mensaje a 
ISSN 1659-3316

Vázquez Parra José Carlos

García Caballero Lorena

Así, guiarse por las emociones puede llegar a ser una forma complementaria de disipar problemas de decisión complejos, ya sea al limitarlas por el hiperracionalismo o bien, resolviendo la indeterminación dentro de una escala de preferencias al tomar una decisión (Elster, 2002, pág. 348).

De igual manera que lo plantea la neuroética, aunque las emociones no resultan ser una fuente confiable de decisiones, por ser variables y altamente afectadas por cuestiones subjetivas o del entorno, si pueden ser adecuadas para mejorar el proceso de elección de los agentes. Así como se refleja en los experimentos de Greene, actuar de manera racional es la tendencia natural que suelen seguir los agentes al momento de tomar una decisión, sin embargo, actuar desde una racionalidad objetiva puede resultar tan conflictivo cuando se evalúa la situación desde la realidad, que, a pesar de tener la respuesta en las manos, el agente puede actuar motivados por las emociones por resultarle una solución más sencilla o menos disonante a sus valores. Aunque esto pudiera resultar ser un buen ejemplo de la famosa akrasia Aristotélica, no lo es así, ya que como lo señala Elster, el actuar motivado por las emociones puede resultar una alternativa más racional cuando el dilema presentado es tan conflictivo que el agente sencillamente no actúa.

Aunque el presente artículo, planteaba un objetivo exclusivamente analítico sobre la acción, desde los enfoques elsteriano y de la neuroética, parece ser que en su proceso de explicación de los elementos ha dado pauta a una reflexión complementaria, que se centra en como las emociones resultan ser un punto en común de ambas propuestas. Ya sea desde una propuesta biológica o desde una teoría de análisis de la racionalidad, la realidad que viven las personas y el hecho de ser agentes de carne y hueso, no permite el que se les encasille y limite al momento de actuar, y aunque en teoría hubiera elementos que no siempre se ven como relevantes, hay situaciones que llevan a que las personas se motiven por los mismos, resultando ser, como en este caso son las emociones, la piedra angular que explica el porqué de su comportamiento.

La Revista Estudios es editada por la Universidad de Costa Rica y se distribuye bajo una Licencia Creative Commons Atribución-NoComercial-CompartirIgual 3.0 Costa Rica. Para más información envíe un mensaje a 
ISSN 1659-3316

Vázquez Parra José Carlos

García Caballero Lorena

\section{Conclusiones: La acción. Más allá de sus explicaciones}

En su texto, Utilitarismo, pro y contra (1981), Bernard Williams señala que el querer generar teorías que busquen explicar o incluso predecir el actuar humano es un punto bastante controvertido, ya que resulta casi imposible suponer que se puede llegar a conocer con plena certeza lo que pasa al momento de tomar una decisión, ya que sencillamente los seres humanos no pueden explicar o comprender aquello que no pueden entender.

Amartya Sen (1987) considera que este deseo de querer explicar el comportamiento se relaciona en gran medida con el institucionalismo trascendental, corriente teorica que cual busca clasificar el comportamiento a partir de esquemas ideales como sustento para las propuestas teoricas, lo que lamentablemente se aleja de las sociedades reales. En contraste con esta perspectiva basada en ideales, Sen considera la necesidad de un enfoque comparativo, mismo que exponga la realidad de las sociedades, ya que en estos entornos es donde las personas actúan y se aproxima más a lo que estos perciben y valoran. Este último enfoque se conecta mucho más con las necesidades y aspiraciones de los individuos, pues se sustenta en aspectos concretos de la vida humana y no en la racionalidad abstracta de las normas. Por ello, este filósofo y economista considera que aquellas teorías como la de la elección racional, que se sustentan en un ideal de razón y en preferencias que se apegan a estándares ideales, tienen claras lagunas y limitaciones al relacionarse con la realidad y el entorno del agente, en contraste con aquellas propuestas que se basan en el análisis de los éxitos y fracasos de sociedades específicas, y los agentes que viven y se desarrollan en ellas.

El presente artículo pretendía hacer una reflexión desde dos enfoques que particularmente reflexionan y buscan explicar el actuar humano, la neuroética y la teórica de la racionalidad elsteriana. El objetivo se centraba en presentar al lector una visión multidisciplinaria integral de las implicaciones que conlleva la elección,

La Revista Estudios es editada por la Universidad de Costa Rica y se distribuye bajo una Licencia Creative Commons Atribución-NoComercial-CompartirIgual 3.0 Costa Rica. Para más información envíe un mensaje a 
las decisiones y el acto en general, para promover de tal manera, la necesidad de considerar elementos que usualmente no se toman en cuenta, y que por ende limitan la posible explicación del comportamiento.

Sin embargo, y así como lo señala Williams y en su momento Sen, la realidad puede resultar más compleja que la posibilidad teórica de explicarla, dando pauta a elementos, como las emociones, que poco se pueden predecir, pero que tienen un claro impacto en los seres humanos. Ya sea una explicación biológica o una reflexión racional, elementos emocionales pueden poner en entredicho la búsqueda de una explicación objetiva del acto, y esta reflexión es lo que hace verdaderamente valioso este texto.

Independientemente del análisis multidisciplinario presentado, la posibilidad de reflexionar sobre la incertidumbre de la realidad y el actuar humano se constituye como un punto de interés para el mundo académico, ya que no se puede dudar que esto es un desafío que permanece latente para cualquier estudioso de la acción. Sea cual sea el abordaje, la teoría de la explicación de los agentes, sus elecciones y su actuar pende inevitablemente de la realidad de los seres humanos, aunque para el infortunio de los teóricos que buscan la objetividad y la explicación certera del comportamiento humano, los individuos no tienen esta dependencia, ya que las acciones no estriban en ningún tipo de explicación, pudiendo ser tan acordes y contradictorias como al individuo le plazca.

\section{(c) (i) (2)}

La Revista Estudios es editada por la Universidad de Costa Rica y se distribuye bajo una Licencia Creative Commons Atribución-NoComercial-CompartirIgual 3.0 Costa Rica. Para más información envíe un mensaje a 
Bibliografía

Bridgeman, B. (1991). Biología del comportamiento y de la mente. Madrid: Alianza.

Damasio, A. (2006). El error de Descartes. Drakontos. Barcelona: Drakontos.

Doménech, A. (1991). Elster y las limitaciones de la racionalidad. En J. Elster, Domar la suerte (págs. 9-49). Barcelona: Paidós.

Elster, J. (1988). Uvas Amargas. Sobre la subversión de la racionalidad. Barcelona: Peninsula.

Elster, J. (1989). Tuercas y Tornillos. Barcelona: Gedisa.

Elster, J. (2000). Las limitaciones del paradigma de la elección racional. Las ciencias sociales en la encrucijada. Madrid: Institució Alfons El Magnanim.

Elster, J. (2002). Alquimias de la mente: Racionalidad y emociones. Barcelona: Paidós.

Elster, J. (2002). Ulises Desatado. Barcelona: Gedisa.

Elster, J. (2007). La explicación del comportamiento social: mas tuercas y tornillos para las ciencias sociales. Barcelona: Gedisa.

Elster, J. (2007). La explicación del comportamiento social: mas tuercas y tornillos para las ciencias sociales. Barcelona: Gedisa.

Elster, J. (2010). L'Irrationalité. Traité critique de l'homme économique, II. Roubaix: Seuil.

Elster, J. (2011). El desinterés, Tratado crítico del hombre económico (I). México: Siglo XXI Editores.

Feito, L. (2015). Neuroética. Las bases neuronales del juicio moral. Madrid: Universidad Complutense de Madrid.

\section{(c) (i) (9) (2)}

La Revista Estudios es editada por la Universidad de Costa Rica y se distribuye bajo una Licencia Creative Commons Atribución-NoComercial-CompartirIgual 3.0 Costa Rica. Para más información envíe un mensaje a 
Revista Estudios, (36), 2018.

ISSN 1659-3316

Junio 2018-Noviembre 2018

Vázquez Parra José Carlos García Caballero Lorena

Gregory, R. (1995). Diccionario Oxford de la mente. Madrid: Alianza.

Hobbes, T. (1989). El Leviatán. Madrid: Alianza.

Illes, J., \& Racine, E. (2002). Imaging or Imagining? A neuroethics challenge infromed by genetics. American Journal of Bioethics(50), 341-344.

Rábade, S. (1994). La razón y lo irracional. Madrid: Editorial Complutense.

Sen, A. (1987). Sobre Ética y Economia. Madrid: Alianza Editorial.

Velasco, J. (2009). Democracia y deliberación pública. Confluencia XXI(6), 71.

La Revista Estudios es editada por la Universidad de Costa Rica y se distribuye bajo una Licencia Creative Commons Atribución-NoComercial-CompartirIgual 3.0 Costa Rica. Para más información envíe un mensaje a revistaestudios.eeg@ucr.ac.cr. 